\title{
BMJ Open Obstetric and non-obstetric surgery during pregnancy: A 20-year Danish population-based prevalence study
}

\author{
Anne Staub Rasmussen, ${ }^{1}$ Christian Fynbo Christiansen, ${ }^{2}$ Niels Uldbjerg, ${ }^{3}$ \\ Mette Nørgaard ${ }^{2}$
}

To cite: Rasmussen AS, Christiansen CF, Uldbjerg N, et al. Obstetric and nonobstetric surgery during pregnancy: A 20-year Danish population-based prevalence study. BMJ Open 2019;9:e028136. doi:10.1136/ bmjopen-2018-028136

- Prepublication history and additional material for this paper are available online. To view these files, please visit the journal online (http://dx.doi. org/10.1136/bmjopen-2018028136).

Received 23 November 2018 Revised 2 March 2019 Accepted 9 April 2019

Check for updates

(c) Author(s) (or their employer(s)) 2019. Re-use permitted under CC BY-NC. No commercial re-use. See rights and permissions. Published by BMJ.

${ }^{1}$ Department of Clinical Epidemiology, Aarhus Universitet, Aarhus, Denmark ${ }^{2}$ Department of Clinical Epidemiology, Aarhus Universitetshospital, Aarhus, Denmark

${ }^{3}$ Department of Obstetrics and Gynecology, Aarhus Universitetshospital, Aarhus, Denmark

Correspondence to Anne Staub Rasmussen; anne@clin.au.dk

\section{ABSTRACT}

Objectives Population-based studies on use of nonobstetric and obstetric surgical procedures during pregnancy are sparse. Therefore, our objective was to estimate the prevalence of surgery during pregnancy, including potential time trends, overall and by trimester and describe the characteristics of pregnant women undergoing surgery.

Design This study is a large nationwide cohort study. Setting From administrative and medical databases, we obtained information about all pregnancies ending in a live birth, a stillbirth or an abortion (spontaneous and induced) in Denmark during 1996-2015. Procedures (excluding caesarean sections) conducted during pregnancy were categorised as a non-obstetric or obstetric surgery and further divided into laparoscopic or non-laparoscopic procedures.

Main outcome measure Main outcome measure is prevalence of surgery during pregnancy.

Results We included 1687176 pregnancies of which 108502 (6.4\%) received 117424 surgical procedures. The prevalence of non-obstetric surgery was almost stable (1.5\% in 1996-1999 to $1.6 \%$ in 2012-2015), whereas non-obstetric abdominal or gynaecological laparoscopic procedures increased from $0.5 \%$ to $0.8 \%$. For appendectomies, the proportion of laparoscopic surgery increased from $4.2 \%$ to $79.2 \%$ during the study period. In 49 pregnancies, surgery for internal herniation was conducted in 2012-2015 versus none in 1996-1999. The prevalence of obstetric surgery, excluding invasive diagnostic tests, increased from $0.2 \%$ to $0.8 \%$. High multiplicity, smoking, increasing age, body mass index (BMI) and parity were factors associated with a high prevalence of surgery during pregnancy.

Conclusions The increase in the prevalence of laparoscopic surgery during pregnancy may reflect a decreased restraint concerning conductance of these surgical procedures during pregnancy. The increasing proportion of laparoscopic procedures complies with clinical recommendations, and the prevalence of surgery during pregnancy varied by multiplicity, smoking status, parity, age and BMI.

\section{INTRODUCTION}

Surgery during pregnancy is of clinical concern. Non-obstetric surgery occurs in approximately $1 \%-2 \%$ of all pregnancies ${ }^{1}$

\section{Strengths and limitations of this study}

High-quality nationwide data.

- Information on pregnancies that end in abortion.

- Main groups of surgical procedures is used, minimising the risk of misclassification.

- Some abortions will be missing in the registries.

- Reporting of invasive diagnostic tests is not complete in the early study period.

and obstetric surgery in more than $20 \%$, with caesarean section being the most frequent procedure. $^{2}$

Most studies concerning fetal and maternal outcome of surgery during pregnancy are small single-centre studies. ${ }^{34}$ The few large national cohort studies tended to focus on specific clinical conditions, for example, appendicitis. ${ }^{56}$ A US study of 1969 pregnant women included a broad range of non-obstetric surgeries during pregnancy ${ }^{7}$ and concluded that major maternal complications and maternal mortality following surgery during pregnancy were rare. A cohort study including almost 6.5 mio pregnancies identified, using the UK Hospital Episode Statistics database found a higher risk of adverse birth outcomes but concluded that the attributable risk was generally low. ${ }^{8}$ The same elevated risk of adverse delivery outcomes was found in a case-control study of 462 non-obstetric surgeries during pregnancy. ${ }^{9}$ In 2011, the Society of American Gastrointestinal Endoscopic Surgeons approved a clinical guideline recommending laparoscopic procedures during any trimester of pregnancy, ${ }^{10}$ and in 2017, the safety of surgery during pregnancy in all trimesters was acknowledged by the Committee on Obstetric Practice and the American Society of Anesthesiologists. ${ }^{11}$ The increasing knowledge about the safety of surgery during pregnancy could possibly implicate a higher prevalence of surgical procedures during pregnancy. To 
our knowledge, no studies have examined time trends in prevalence and distribution in relation to trimester of surgery during pregnancy excluding caesarean sections. With this study, we wanted to provide such an overview on the development in the field of surgery during pregnancy in Denmark in the last 20 years.

We examined the prevalence and type of non-obstetric and obstetric surgical procedures performed during pregnancy and characterised pregnant women undergoing surgery. Specifically, we wanted to examine (1) the time trend in surgical procedures conducted during pregnancy focusing on abdominal procedures (diagnostic procedures, surgery for internal herniation and appendectomies), gynaecological procedures (sterilisations and ovarian cyst surgery) and obstetric procedures other than caesarean section (cerclages, invasive diagnostic tests and other surgeries); (2) any change in conduction of laparoscopic versus non-laparoscopic gynaecological and abdominal surgery during time and (3) characteristics of surgically treated women.

\section{MATERIAL AND METHODS}

We conducted this nationwide prevalence study in Denmark within a population of 5.7 million inhabitants. ${ }^{12}$ The Danish population has unrestricted access to a tax-supported healthcare system allowing all Danish citizens to have equal access to hospital and specialist treatment. All treatments in public as well as private hospitals are registered.

Every Danish citizen is assigned a personal identification number at birth or immigration (the Danish Civil Registration System [CPR] number). This unique identification number contains information on birth date and sex and allows individual-level electronic linkage between population-based registries. In this study, we linked data from the Danish Civil Registration System, ${ }^{13}$ the Danish National Patient Registry (DNPR) ${ }^{14}$ and the Danish Medical Birth Registry. ${ }^{15}$

We identified all Danish female citizens aged 15-54 years who gave birth (live birth or stillbirth) or had an induced or spontaneous abortion during 1996-2015. Women giving birth were identified through the Danish Medical Birth Registry, while induced and spontaneous abortions were retrieved from the DNPR. Both single and multiple births were counted as one pregnancy. Each woman could contribute with an unlimited number of pregnancies. The Danish Medical Birth Registry was established in 1973 and contains information on all deliveries in Denmark, both home deliveries and hospital deliveries. Live births at all gestational ages and stillbirths with a gestational age $\geq 22$ weeks are included. The registry consists of data collected prospectively by the midwife attending birth. Information on mother and child(ren) are collected in one record. Maternal information includes: number of previous stillbirths, parity, age, marital status, smoking status, body mass index (BMI) (since 2003) and citizenship. ${ }^{16}$
Since 1977, it has been mandatory for Danish hospitals to report data on all non-psychiatric hospital admissions to the DNPR. Since 1995, emergency room contacts and contacts to hospital specialist clinics has been registered as well. Until 1994, diagnoses were registered according to the Danish version of International Classification of Diseases (ICD) 8th revision, but since then, the Danish version of ICD 10th revision has been used. ${ }^{16}$

All patients undergoing surgery are assigned a surgical code in the DNPR. The surgical procedures are registered immediately after surgery by the surgeon responsible for the procedure and coded according to a Danish version of the Nordic Medico-Statistical Committee Classification of Surgical Procedures. ${ }^{17}$ We included all surgical procedures except caesarean sections and procedures related to abortions (see the online supplementary appendix S1 for the specific codes) in pregnant women in the years 1996-2015. One pregnancy could account for more than one surgical procedure if there were more than one admission. We only included the procedure recorded as the primary in each admission. We categorised the type of surgery into non-obstetric surgery including abdominal surgery (subcategories diagnostic procedures, surgery for internal herniation and appendectomy), gynaecological surgery (subcategories sterilisations or ovarian cyst surgery), orthopaedic surgery, other non-obstetric surgery, obstetric surgery including cerclage (abdominal or vaginal, with vaginal cerclage subdivided by gestational age at time of cerclage) and invasive diagnostic tests. When relevant, procedures were subdivided into open or laparoscopic.

From the Danish Medical Birth Registry, we extracted information on demographics (maternal age at birth, parity, multiplicity, BMI and smoking status) for all pregnancies $>22$ weeks of gestation. Information on maternal and gestational age in women who had a miscarriage or termination of pregnancy before 22 weeks of gestation was retrieved from the DNPR. Maternal age was categorised in years as $<20,20-29,30-39$ or $\geq 40$. Parity was divided into nulliparous or parous, multiplicity in singleton or multiple pregnancies, BMI in the categories $<18.5$, 18.5$24.9,25-29.9$ and $\geq 30$. Smoking status was reported as being smoker or non-smoker.

Surgery during pregnancy was defined as a registration of surgery in the period from beginning of the last menstrual period to date of delivery or abortion. Date of beginning of the last menstrual period was calculated as date of delivery minus gestational age in days at delivery. We determined trimester of surgery according to length of pregnancy at the date of surgery, calculated as date of surgery minus date of beginning of last menstrual period. First trimester was defined as surgery on day $0-83$ of gestation, second trimester as surgery on day 84-195 of gestation and third trimester as surgery on day 196-315 of gestation.

For all pregnant women, we tabulated demographics. The prevalence of each of the above mentioned variables was calculated for subgroups of surgical procedures (table 1). The study period was separated in 4 year groups according to date of surgery (1996-1999, 2000-2003, 


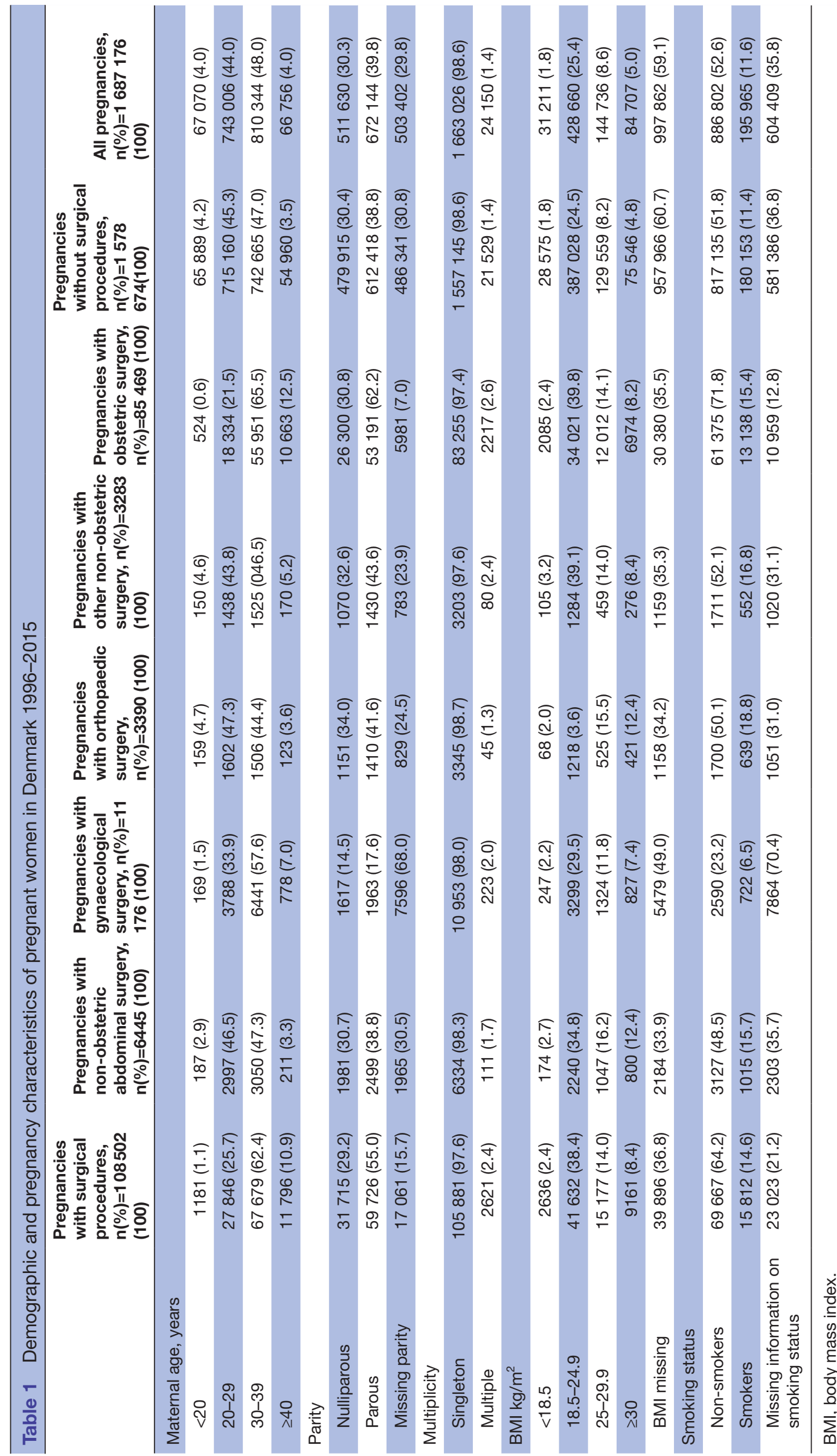




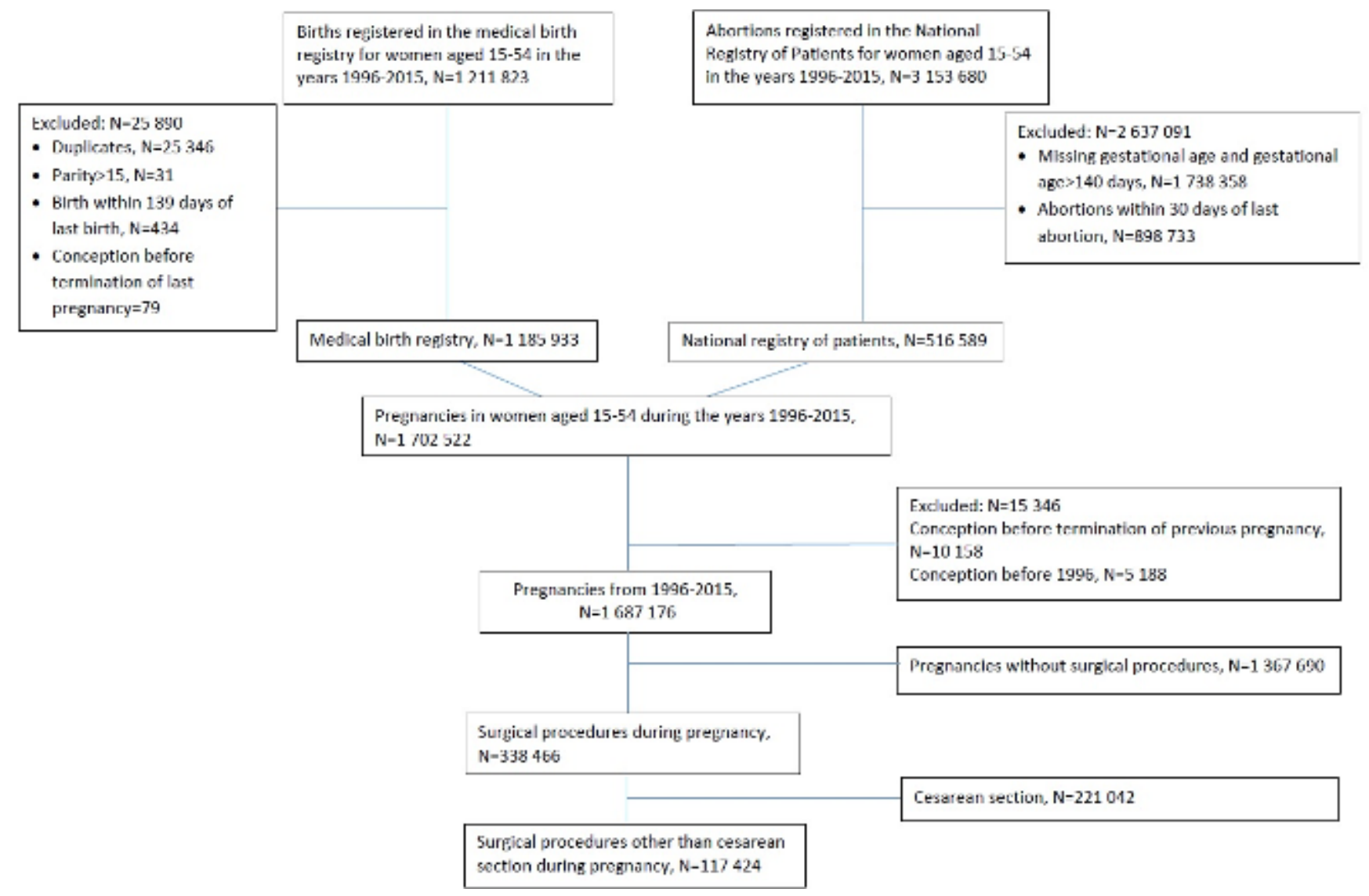

Figure 1 Flow chart providing overview on included women.

2004-2007, 2008-2011, 2012-2015). The aforementioned types of obstetric and non-obstetric surgeries performed in pregnant women were described according to year groups, and the proportion of surgical procedures in each group compared with the total number of pregnancies was calculated. The frequency of non-obstetric surgery was analysed in terms of trimester and type of surgery. Furthermore, the prevalence of laparoscopic and non-laparoscopic abdominal and gynaecological surgery was examined for each year group and according to trimesters as well. Data were analysed using the statistical software package STATA V.13 (Stata).

\section{Ethical approval}

This study was approved by the Danish Data Protection Agency (record number 2015-57-0002, Aarhus University record number 2016-051-000001-522). Ethical approval is not required for non-interventional registry-based studies in Denmark.

\section{Patient and public involvement statement}

Our study is a non-interventional registry-based study, and no patient or public were involved.

\section{RESULTS}

Our cohort consisted of 1687176 pregnancies registered in Denmark during 1996-2015 (see flow chart in figure 1). Of these, 1183774 (70.2\%) ended in a live birth or stillbirth $\geq 20$ weeks gestational age and 503402 pregnancies $(29.8 \%)$ in induced or spontaneous abortions. For the entire cohort, the median maternal age at time of birth or abortion was 30 years, $30.3 \%$ were nulliparous and 1663026 (98.6\%) had singleton pregnancies (table 1). The total number of pregnancies decreased from 364489 in 1996-1999 to 262900 in 2012-2015 (table 2).

Within the cohort, 108502 (6.4\%) had at least one surgical procedure excluding caesarean sections. The prevalence increased from $4.9 \%$ in 1996-1999 to $6.5 \%$ in 2012-2015. The number of procedures $(7.0 \%)$ was slightly higher than the number of pregnancies with procedures, reflecting that some women underwent several procedures in the same pregnancy (table 2).

Surgically treated women had higher median age (34 years) and slightly fewer had singleton pregnancies (97.6\%), $14.6 \%$ were smokers, and $8.4 \%$ had a BMI $\geq 30$.

During the study period, the prevalence of abdominal surgery during pregnancy increased from $0.3 \%$ to $0.5 \%$ (table 2). The prevalence in second and third trimester increased correspondingly (figure 2). Surgery for internal herniation was not conducted in the early study period but occurred in 49 cases between 2012 and 2015. The use of laparoscopic procedures increased in the end of the study period (figure 3 ), especially in the second trimester (figure 4). 
Table 2 Number and prevalence of pregnancies with different types of surgical procedures in Denmark 1996-2015

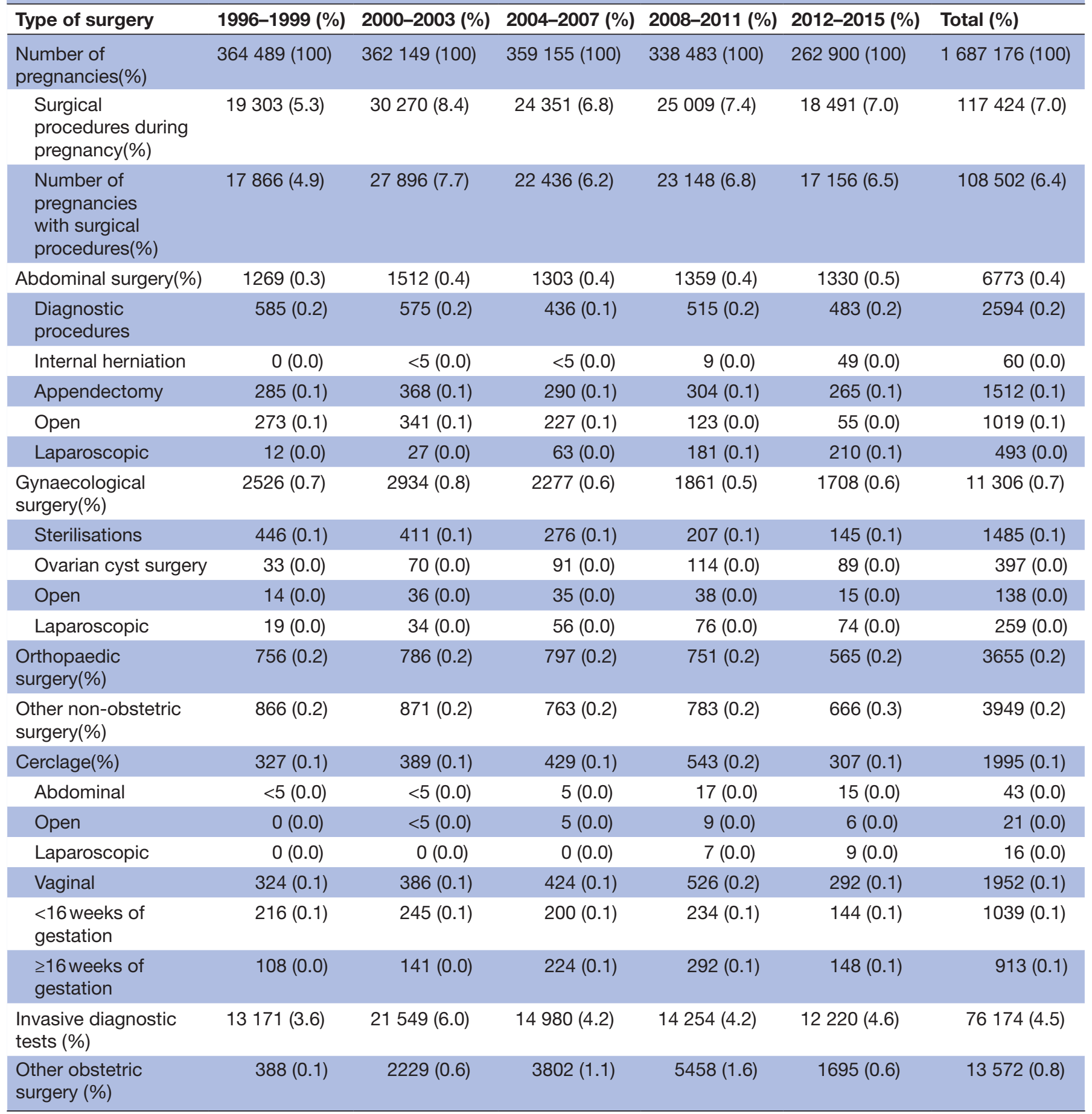

During the study period, the proportion of appendectomies conducted laparoscopic increased in all trimesters $(4.2 \%$ to $79.2 \%)$ but most in first and second trimester (figure 5).

The prevalence of abdominal surgery did not vary by age, parity, multiplicity and maternal smoking status (table 1), while women with a high BMI had increased prevalence of abdominal surgery during pregnancy.

Through the study period, the overall prevalence of gynaecological surgery during pregnancy varied between $0.5 \%$ and $0.8 \%$ (table 2). Conduction of sterilisations and ovarian cyst surgery remained stable. Gynaecological surgery occurred predominantly in the first trimester (figure 2).

The prevalence of gynaecological surgery during pregnancy was $0.3 \%$ in women $<20$ years and $1.2 \%$ for women $>40$. In multiple pregnancies, it was $0.9 \%$ versus $0.7 \%$ in singleton pregnancies. The prevalence of gynaecological surgery increased slightly with increasing BMI. While the prevalence of non-laparoscopic surgery decreased in first trimester over time, it remained stable in the second and third trimester. 


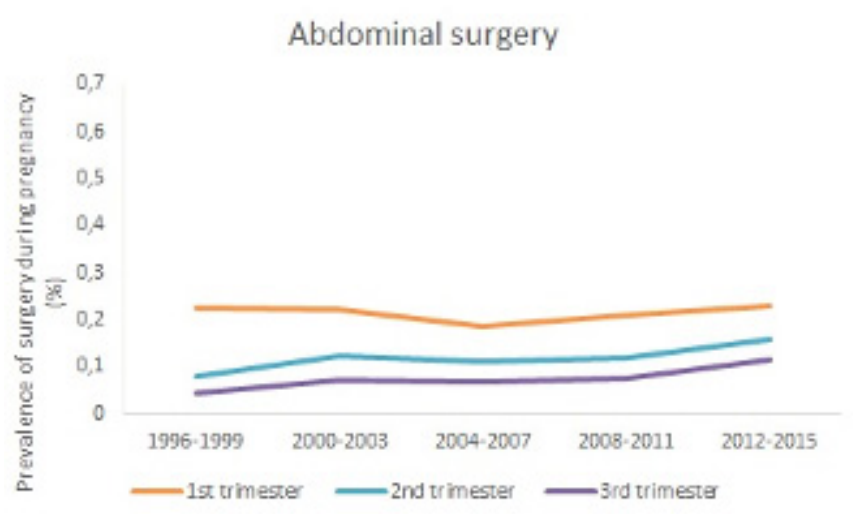

Gynecologic surgery

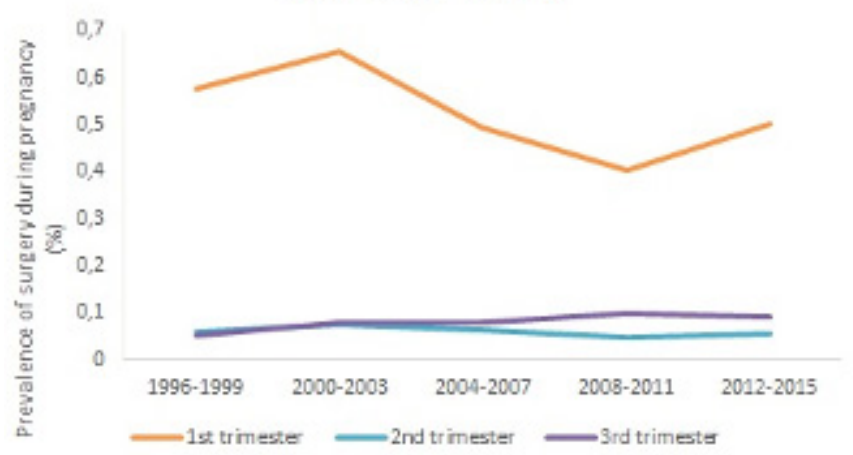

Orthopedic surgery

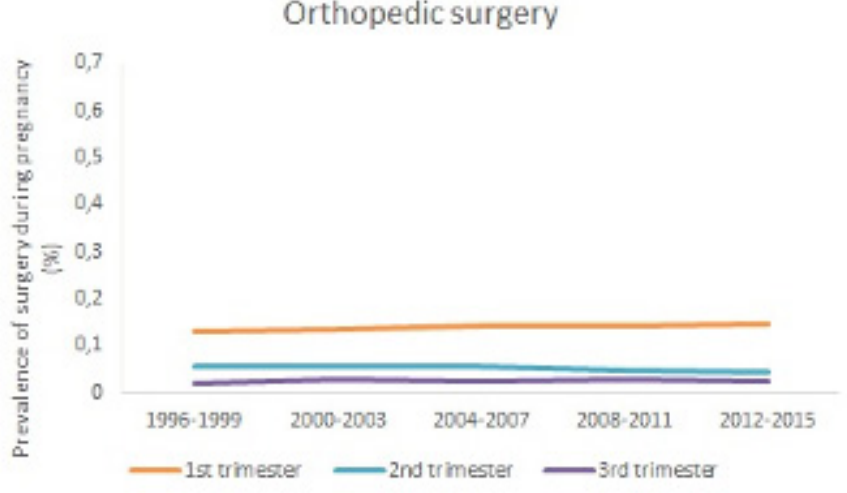

Other non-obstetric surgery

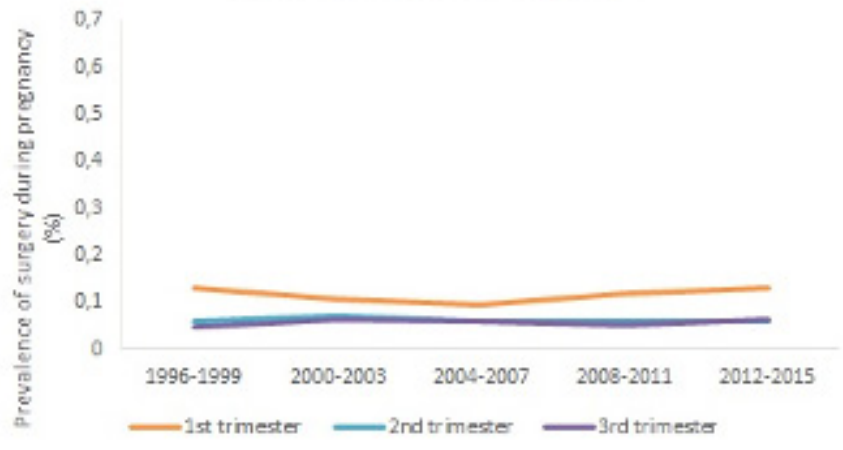

Figure 2 Development over time in prevalence of surgery in the three trimesters of pregnancy during 1996-2015.

For orthopaedic surgery, the overall prevalence was $0.2 \%$, and we observed a stable prevalence throughout the study period (table 2). The prevalence in each trimester was stable as well (figure 2), but the observed prevalence of orthopaedic surgery was highest among women with high BMI (table 1).

Other non-obstetric surgery had an overall prevalence of $0.3 \%$ in 2012-2015 (table 2). The prevalence in first, second and third trimester was stable throughout the period as well (figure 2). There was no major difference in prevalence of other non-obstetric surgery in subgroups of pregnant women with different characteristics (table 1).

With a prevalence of $5.4 \%$, obstetric surgery was more common during pregnancy than non-obstetric surgery. The prevalence of specific obstetric procedures is listed

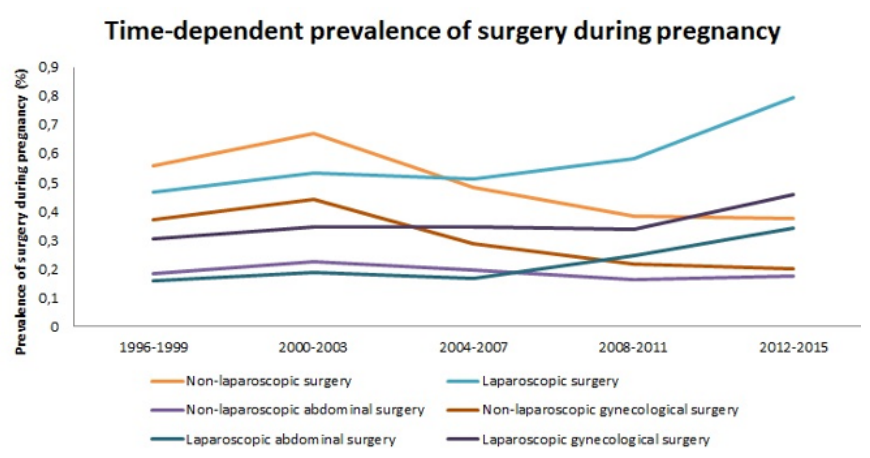

Figure 3 Development in prevalence of laparoscopic and non-laparoscopic surgery during pregnancy in 1996-2015. in table 2. Women aged $<20$ had a $0.8 \%$ prevalence of obstetric procedures versus $16 \%$ for women aged $\geq 40$. Also for parity $>1$, multiplicity and high BMI, a higher prevalence of obstetric surgery was observed (table 1). The increased prevalence in multiple pregnancies could partly be explained by the conduction of fetal reductions and laser treatments of the placenta (data not shown). The prevalence of obstetric surgery was $6.9 \%$ in non-smokers and $6.7 \%$ in smokers (table 1 ).

\section{DISCUSSION}

Among Danish pregnant women, the proportion who undergo non-obstetric surgery has been almost stable over a 20-year period. An increase was observed for non-obstetric laparoscopic procedures. The prevalence of surgery during pregnancy differed by maternal characteristics, with the highest observed prevalence among women with high age, high BMI, high parity, smokers and multiple pregnancies.

The increasing use of laparoscopic procedures after 2011 probably reflects the recommendations from the Society of American Gastrointestinal Endoscopic Surgeons published in 2011. ${ }^{10}$ These guidelines concluded that the recent data at hand confirmed the safety of laparoscopy during all trimesters for many surgical conditions. We found, however, that while the use of laparoscopy increased in second trimester, the use remained stable in third trimester. Accordingly, the use of open surgery did 

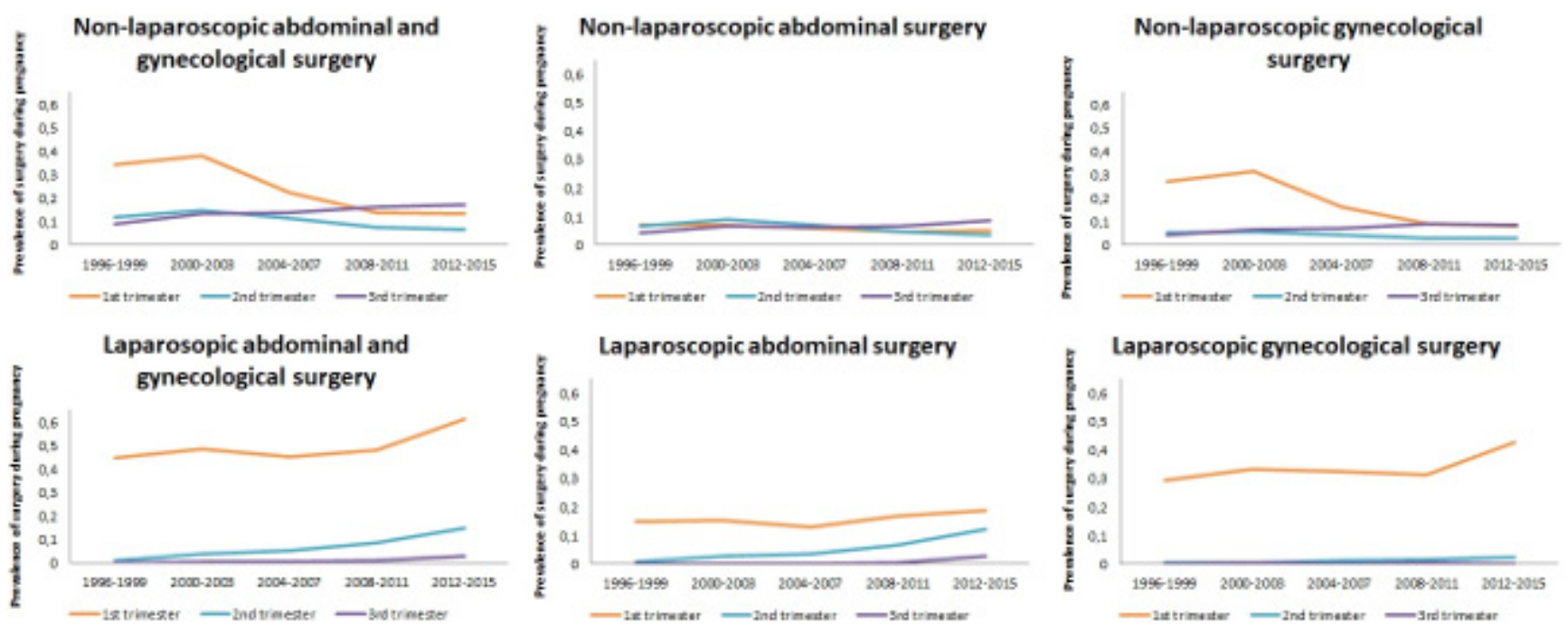

Figure 4 Development over time in prevalence of laparoscopic and non-laparoscopic surgery in the three trimesters of pregnancy during 1996-2015.

not decrease in the third trimester. We may only speculate of the reasons for this lack of decrease in the third trimester open surgery. Though it is considered safe to conduct laparoscopic surgery in the third trimester, it may not be possible to perform laparoscopy due to technical difficulties leaving open surgery as the only applicable treatment. ${ }^{18}$ The increase in abdominal surgery during our study period was mainly driven by an increase in laparoscopic cholecystectomy. Since cholecystitis can be treated with watchful waiting, ${ }^{19}$ it is possible that the 2011 recommendations lead to declining use of watchful waiting and accordingly increased use of surgery. The increasing need for assisted reproduction associated with obesity and increased maternal age is well established ${ }^{20-22}$; hence, our finding that women with high BMI and advanced maternal age were most likely to undergo surgery during pregnancy complements previous findings regarding assisted reproduction technology, ${ }^{20}{ }^{23}$ showing that the use of assisted reproduction technology increases the risk of pregnancy complications treated surgically. ${ }^{24}$

As opposed to these increases, the number of invasive tests decreased after 2004, a shift which Vestergaard $e t a l^{26}$

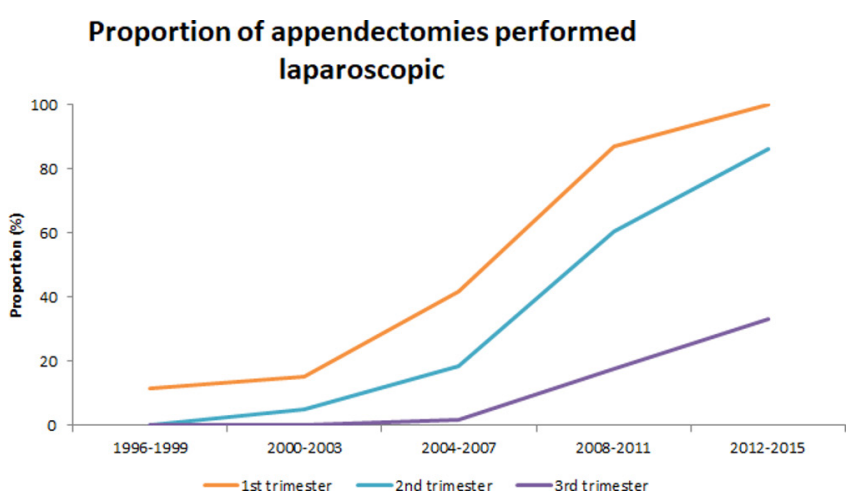

Figure 5 Development in proportion of appendectomies conducted laparoscopically in each trimester in 1996-2015. explained by a change in the criteria for offering prenatal diagnostics. $^{27}$

\section{Strengths and limitations}

A strength of this study is our access to high-quality nationwide registries ${ }^{15} 2829$ concerning pregnant women in Denmark 1996-2015, covering the whole nation equally which minimised potential selection bias. Numerous validation studies concerning the validity of single procedure codes in the DNPR have been conducted, most of them showing positive predictive values between $90 \%$ and $100 \% .{ }^{3031}$ Furthermore, we had access to information on pregnancies resulting in elective or spontaneous abortions which gave us the opportunity to evaluate surgery performed in early pregnancy as well.

Some limitations should, however, be considered when interpreting the results. Due to unrecognised pregnancy, some women with very early spontaneous abortions would not have been in contact with the hospital system and therefore not included in our study population.

The registration of invasive diagnostic tests in the DNPR increased between 1996-1999 and 2000-2003, ${ }^{26}$ and the prevalence of invasive diagnostic tests before 2003 is thus an underestimate.

Coding practice of surgical procedures may have changed during our 20-year study period. However, since we categorised the procedures as main groups, we do not expect such changes to substantially influence our estimates. In conclusion, we found an increasing prevalence of laparoscopic surgery during pregnancy in the 20-year study period, corresponding to the publication of clinical recommendations. The main part of procedures were conducted in first trimester of pregnancy and the prevalence of surgery during pregnancy increased with multiplicity, smoking, parity, increasing maternal age and increasing BMI. 
Acknowledgements Thanks to Peter Rask for help defining codes used for surgery for internal herniation.

Contributors ASR conducted data-management, wrote the first draft and revised editions of the article. NU provided insights to the interests of obstetrics and gynecologists to make the paper clinically relevant, and he contributed with thorough reading of the manuscript in several revisions. CFC provided epidemiological expertise and view to the paper in order to ensure the correctness of analysis and statements and revised the manuscript several times. MN also contributed with epidemiological expertise and helped keeping track on the relevancy of the conducted analyses. She as well helped in the revision from draft to submittable paper.

Funding Funding of this project was provided by Aarhus University, Department of Clinical Epidemiology Aarhus University Hospital and Knud og Edith Eriksens Mindefond.

Competing interests None declared.

Patient consent for publication Not required.

Provenance and peer review Not commissioned; externally peer reviewed.

Data sharing statement № additional data are available.

Author note Strobe: Where relevant, we followed the STROBE guideline, but because of the descriptive nature of the manuscript, not all points were relevant.

Open access This is an open access article distributed in accordance with the Creative Commons Attribution Non Commercial (CC BY-NC 4.0) license, which permits others to distribute, remix, adapt, build upon this work non-commercially, and license their derivative works on different terms, provided the original work is properly cited, appropriate credit is given, any changes made indicated, and the use is non-commercial. See: http://creativecommons.org/licenses/by-nc/4.0/.

\section{REFERENCES}

1. Ní Mhuireachtaigh R, O'Gorman DA. Anesthesia in pregnant patients for nonobstetric surgery. J Clin Anesth 2006;18:60-6.

2. Osterman Mjk MJA. Primary cesarean delivery rates, by state: Results from the revised birth certificate, 2006-2012. 2014.

3. Soriano D, Yefet Y, Seidman DS, et al. Laparoscopy versus laparotomy in the management of adnexal masses during pregnancy. Fertil Steril 1999;71:955-60.

4. Gurbuz AT, Peetz ME. The acute abdomen in the pregnant patient. Is there a role for laparoscopy?. Surg Endosc 1997;11:98-102.

5. Abbasi N, Patenaude V, Abenhaim HA. Evaluation of obstetrical and fetal outcomes in pregnancies complicated by acute appendicitis. Arch Gynecol Obstet 2014;290:661-7.

6. Abbasi N, Patenaude V, Abenhaim HA. Management and outcomes of acute appendicitis in pregnancy-population-based study of over 7000 cases. BJOG 2014;121:1509-14.

7. Erekson EA, Brousseau EC, Dick-Biascoechea MA, et al. Maternal postoperative complications after nonobstetric antenatal surgery. $J$ Matern Fetal Neonatal Med 2012;25:2639-44.

8. Balinskaite V, Bottle A, Sodhi V, et al. The risk of adverse pregnancy outcomes following nonobstetric surgery during pregnancy: estimates from a retrospective cohort study of 6.5 million pregnancies. Ann Surg 2017;266:260-6.

9. Yu CH, Weng SF, Ho CH, et al. Pregnancy outcomes following nonobstetric surgery during gestation: a nationwide populationbased case-control study in Taiwan. BMC Pregnancy Childbirth 2018;18:460.
10. Pearl J, Price R, Richardson W, et al. Society of american gastrointestinal endoscopic s. guidelines for diagnosis, treatment, and use of laparoscopy for surgical problems during pregnancy. Surgical endoscopy 2011;25:3479-92.

11. Committee on Obstetric Practice and the American Society of Anesthesiologists. Committee opinion no. 696: Nonobstetric surgery during pregnancy. Obstet Gynecol 2017;129:777-8.

12. Denmark S. Befolkning og befolkningsfremskrivning. $2016 \mathrm{http}: / /$ www.dst.dk/da/Statistik/emner/befolkning-og-befolkningsfrems krivning/folketal (Accessed 23 Apr 2019).

13. Schmidt M, Pedersen L, Sørensen HT. The Danish Civil Registration System as a tool in epidemiology. Eur J Epidemiol 2014;29:541-9.

14. Lynge E, Sandegaard JL, Rebolj M. The Danish National Patient Register. Scand J Public Health 2011;39(7 Suppl):30-3.

15. Knudsen LB, Olsen J. The Danish Medical Birth Registry. Dan Med Bull 1998;45:320-3.

16. Sørensen HT, Christensen T, Schlosser HK, et al. Use of Medical Databases in Clinical Epidemiology. 2nd ed. Aarhus: Aarhus University, 2009.

17. Berg L, Fresvig T. Classification of surgical procedures (NCSP). Version 2009:16.

18. Iwamura S, Hashida H, Yoh T, et al. Laparoscopic appendectomy during the third trimester: Case presentation and literature review. Asian J Endosc Surg 2018;11:413-6.

19. Ibiebele I, Schnitzler M, Nippita T, et al. Outcomes of gallstone disease during pregnancy: A population-based data linkage study. Paediatr Perinat Epidemiol 2017;31:522-30.

20. Bellver J, Rossal LP, Bosch E, et al. Obesity and the risk of spontaneous abortion after oocyte donation. Fertil Steril 2003;79:1136-40.

21. Farquhar CM, Bhattacharya S, Repping S, et al. Female subfertility. Nat Rev Dis Primers 2019;5:7.

22. Ramsay JE, Greer I, Sattar N. ABC of obesity. Obesity and reproduction. BMJ 2006;333:1159-62.

23. Hassold T, Chiu D. Maternal age-specific rates of numerical chromosome abnormalities with special reference to trisomy. Hum Genet 1985;70:11-17.

24. Spitzer D, Wirleitner B, Steiner $\mathrm{H}$, et al. Adnexal torsion in pregnancy after assisted reproduction - case study and review of the literature. Geburtshilfe Frauenheilkd 2012;72:716-20.

25. Vloeberghs V, Peeraer K, Pexsters A, et al. Ovarian hyperstimulation syndrome and complications of ART. Best Pract Res Clin Obstet Gynaecol 2009;23:691-709.

26. Vestergaard $\mathrm{CH}$, Lidegaard $\varnothing$, Tabor A. Invasive prenatal diagnostic practice in Denmark 1996 to 2006. Acta Obstet Gynecol Scand 2009;88:362-5.

27. Sundhedsstyrelsen. Retningslinjer for fosterdiagnostik - prænatal information, risikovurdering, rådgivning og diagnostik [The Danish National Board of Health: Guidelines for prenatal diagnosis, risk assessement, counselling, and diagnosis] (in Danish. No abstract available). 2004. Contract No: Report

28. Sneider K, Langhoff-Roos J, Sundtoft IB, et al. Validation of second trimester miscarriages and spontaneous deliveries. Clin Epidemiol 2015;7:517-27.

29. Schmidt M, Schmidt SA, Sandegaard JL, et al. The Danish National Patient Registry: a review of content, data quality, and research potential. Clin Epidemiol 2015;7:449-90.

30. Kjaergaard J, Clemmensen IH, Thomsen BL, et al. Validity of diagnoses of and operations for nonmalignant gynecological conditions in the Danish National Hospital Registry. J Clin Epidemiol 2002;55:137-42.

31. Harboe KM, Anthonsen K, Bardram L. Validation of data and indicators in the Danish Cholecystectomy Database. Int J Qual Health Care 2009;21:160-8. 